\title{
WEEKSITA RICA EM BÁRIO DE PERUS, MUNICÍPIO DE SÃO PAULO
}

\author{
D.Atencio ${ }^{1}$ \\ J.M.V.Coutinho ${ }^{1}$ \\ S.Andrade ${ }^{1}$ \\ E.H.Mishima ${ }^{2}$ \\ M.L.Maenaka ${ }^{2}$
}

Amostras contendo weeksita rica em bário foram coletadas na pedreira de propriedade de Domingas Dell'Antonia Tosold \& Cia Ltda., situada à Avenida Raimundo Pereira de Magalhães n 15.221, bairro de Perus, Município de São Paulo. O mineral weeksita, $\mathrm{K}_{2}\left(\mathrm{UO}_{2}\right)\left(\mathrm{Si}_{6} \mathrm{O}_{15}\right) \cdot 4 \mathrm{H}_{2} \mathrm{O}$, ortorrômbico, originalmente denominado "gastunita" por HONEA (1959), foi descrito por OUTERBRIDGE et al. (1960). O nome weeksita foi mantido devido a muitas descrições conflitivas de "gastunita" (HABERLANDT \& SCHIENER, 1951; WALENTA, 1960). A weeksita de Perus apresenta substituição de K por Ba em maior proporção que a verificada nas demais amostras citadas na literatura. Referências bibliográficas sobre a geologia e a mineralogia do pegmatito de Perus podem ser obtidas em ATENCIO et al. (1991).

A weeksita constitui crostas pulverulentas de cor amarela que preenchem fraturas do turmalina granito, localmente pegmatítico, de Perus. Todavia, esta forma de ocorrência é comum a diversos minerais uraníferos do local; entre várias dezenas de amostras deste tipo estudadas, apenas seis eram portadoras de weeksita. Verificou-se íntima associação entre weeksita, uranofânio-beta, autunita e saponita, sendo que somente uma das amostras (PS $128 \mathrm{C}-4$ ) era constituída exclusivamente por weeksita.

Ao microscópio petrográfico, a weeksita rica em bário de Perus apresenta-se

\footnotetext{
1 Departamento de Mineralogia e Petrologia, Instituto de Geociências/USP, São Paulo.

${ }^{2}$ Graduação, Instituto de Geociências/USP, São Paulo.
} 
como agregados fibrosos muito finos, de cor amarela, onde apenas algumas das propriedades ópticas puderam ser avaliadas. O mineral é aparentemente biaxial negativo, $\operatorname{com} \beta$ (medido em quatro amostras) variando de 1,603 a 1,605, $\gamma$ (medido unicamente em uma amostra) $=1,609$, birrefringência 0,010 a $0,020,2 \mathrm{~V}_{\mathrm{x}}=70$ a $85^{\circ}, \mathrm{Y} \wedge \mathrm{c}=\mathrm{O}$ a $20^{\circ}$, forte dispersão $\mathrm{r}>\mathrm{v}$. Estas características ópticas coincidem com as das demais amostras de weeksita descritas na literatura.

A weeksita rica em bário de Perus não apresenta fluorescência sob luz ultravioleta de ondas longas (366 nm) e ondas curtas (254 nm).

A weeksita cristaliza no sistema ortorrômbico, grupo espacial Pnnb. Um difratograma de raios X foi obtido para a amostra PS $128 \mathrm{C}-4$, utilizando-se radiação $\mathrm{CuK}_{\alpha} \mathrm{e}$ filtro de Ni (Tabela 1). O padrão verificado para o mineral de Perus é virtualmente idêntico ao da weeksita (PDF 12-462) e também ao do mineral meta-haiweeíta, $\mathrm{Ca}\left(\mathrm{UO}_{2}\right)_{2}\left(\mathrm{Si}_{2} \mathrm{O}_{5}\right)_{3} \cdot \mathrm{nH}_{2} \mathrm{O}$ (PDF 12-722) e ao do composto sintético $\mathrm{Na}_{2}\left(\mathrm{UO}_{2}\right)_{2}\left(\mathrm{Si}_{2} \mathrm{O}_{5}\right)_{3} \cdot 4 \mathrm{H}_{2} \mathrm{O}$ (PDF 12-461), todos isoestruturais. Os parâmetros da cela unitária calculados para o mineral de Perus acham-se comparados aos da weeksita de Thomas Range, Utah, Estados Unidos, na Tabela 2.

As amostras contendo weeksita foram analisadas qualitativamente por fluorescência de raios $\mathrm{X}$ de energia dispersiva (EDS). $\mathrm{O}$ resultado obtido para a amostra PS $128 \mathrm{C}-4$ é apresentado na Figura 1 . O pico mais intenso do $\mathrm{K}$ coincide com o segundo pico mais intenso do $U$, o que impede estimar sua proporção relativa na amostra. O segundo pico mais intenso do $\mathrm{K}$, por sua vez, coincide com o pico mais intenso do $\mathrm{Ca}$. Os picos referentes ao $\mathrm{Ba}$ também foram observados nas amostras contendo misturas entre weeksita e outros minerais.

Dados químicos quantitativos foram obtidos apenas para $\mathrm{K}, \mathrm{Na}, \mathrm{Ca}$ e $\mathrm{Ba}$, devido à pequena disponibilidade de material puro (amostra PS $128 \mathrm{C}-4$ ). 2,9 mg do material foram dissolvidos por $\mathrm{H}_{2} \mathrm{SO}_{4}$ e $\mathrm{HF}$, avolumando-se a solução para $25 \mathrm{ml}$. Análises efetuadas em fotômetro de chama B-262 forneceram como resultados $3,22 \% \mathrm{~K}_{2} \mathrm{O}$ e $0,81 \% \mathrm{Na}_{2} \mathrm{O}$. A partir de 2,6 mg de material, foi realizada uma segunda preparação, com $\mathrm{HNO}_{3} \mathrm{e} \mathrm{HF}$, avolumando-se a solução para $25 \mathrm{ml}$, o que possibilitou a análise de $\mathrm{Ba}$ e $\mathrm{Ca}$ em espectrômetro de absorção atômica Carl Zeiss, verificando-se a presença de $4,88 \% \mathrm{BaO}$ e $0,60 \% \mathrm{CaO}$. A fórmula química do mineral de Perus, considerando-se teores ideais de $\mathrm{UO}_{3}, \mathrm{SiO}_{2} \mathrm{e}_{2} \mathrm{O}$, é $\left(\mathrm{K}_{0,76}{ }^{\mathrm{Ba}} 0,35^{\mathrm{Na}}{ }_{0,29} \mathrm{Ca}_{0,12}\right) \Sigma=1,52\left(\mathrm{UO}_{2}\right)_{2}\left(\mathrm{Si}_{2} \mathrm{O}_{5}\right)_{3} \cdot 4 \mathrm{H}_{2} \mathrm{O}$.

O grupo da weeksita é constituído pelos minerais weeksita e meta-haiweeíta, ambos incompletamente estudados. Dados estruturais parciais são disponíveis somente para a weeksita (STOHL \& SMITH, 1981), tendo sido verificada a presença de cadeias silicáticas com $\mathrm{UO}_{2}$. A posição dos átomos de $\mathrm{K}$ e das moléculas de $\mathrm{H}_{2} \mathrm{O}$ não foi revelada. 
Análogos sintéticos de $\mathrm{K}, \mathrm{K}+\mathrm{Na}, \mathrm{Na}, \mathrm{NH}_{4}$ e $\mathrm{H}_{3} \mathrm{O}$ foram cristalizados em laboratório e apresentaram padrões de difração de raios X essencialmente idênticos (HONEA, 1959), não tendo sido, entretanto, obtidos cristais de dimensões suficientes para estudos estruturais. A introdução do Ba na posição do $\mathrm{K}$ já foi observada em amostras de weeksita de outras localidades: $1,4 \%$ em peso de $\mathrm{BaO}$ na amostra de Thomas Range (OUTERBRIDGE et al., 1960); 1,90 e 0,19\% em peso de $\mathrm{BaO}$ em duas amostras do Afeganistão (YEREMENKO et al., 1977). Esta substituição é consideravelmente mais extensa, porém, na amostra proveniente de Perus. A possibilidade de substituição de diversos cátions na weeksita, sem modificações estruturais significativas, implica na eventual descoberta futura de novas espécies.

\section{AGRADECIMENTOS}

Os autores agradecem a R.Hypolito, C.L.A.Guimarães, F.M.S. Carvalho e R.Neumann por suas valiosas sugestões.

\section{REFERÊNCIAS BIBLIOGRÁFICAS}

ATENCIO, D.; NEUMANN, R.; SILVA, A.J.G.C; MASCARENHAS, Y.P. (1991) Phurcalite from Perus, São Paulo, Brazil, and redetermination of its crystal structure. The Canadian Mineralogist, 29(1).

HABERLANDT, H. \& SCHIENER, A. (1951) Die Mineral- und Elementvergesellschaftung das Zentralgneisgebietes von Badgastein (Hohe Tauren). Tschermaks Mineralogische und Petrographische, Mitteilungen. $3^{\text {a }}$ série, (2):307-313.

HONEA, R.M. (1959) New data on gastunite, an alkali uranyl silicate. American Mineralogist, 44(9-10):1047-1056.

OUTERBRIDGE, W.F.; STAATZ, M.H.; MEYROWITZ, R.; POMMER, A.M. (1960) Weeksite, a new uranium silicate from the Thomas Range, Juab County, Utah. American Mineralogist, 45(1):39-52. 
STOHL, F.V. \& SMITH, D.K. (1981) The crystal chemistry of the uranyl silicate minerals. American Mineralogist, 66(5-6):610-625.

WALENTA, K. (1960) Haiweeit (Gastunit) von Badgastein. Neues Jahrbuch fïr Mineralogie, Monatschefte, p.37-47.

YEREMENKO, G.K.; IL'MENOV, Ye.S.; AZIMI, N.A (1977) Find of weeksite-group minerals in Afghanistan, Doklady Akademii Nauk SSSR, 237(1-6):226-228. 


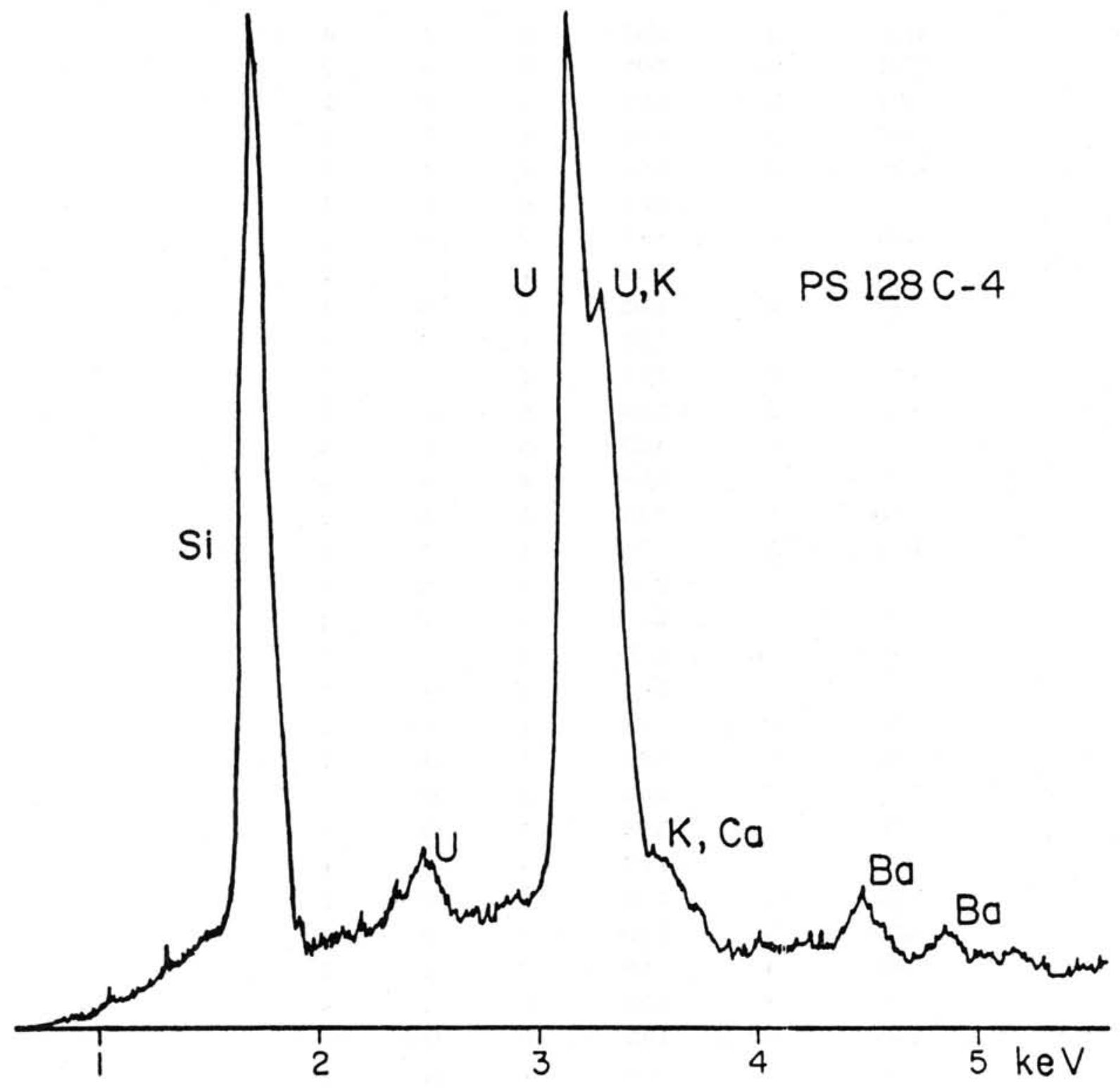

Figura 1 - Padrão de EDS (fluorescência de raios $\mathrm{X}$ de energia dispersiva) da weeksita rica em bário de Perus (amostra PS $128 \mathrm{C}-4$ ). 
TABELA 1 - Padrão de difratometria de raios X da weeksita rica em bário de Perus (amostra PS 128 C-4)

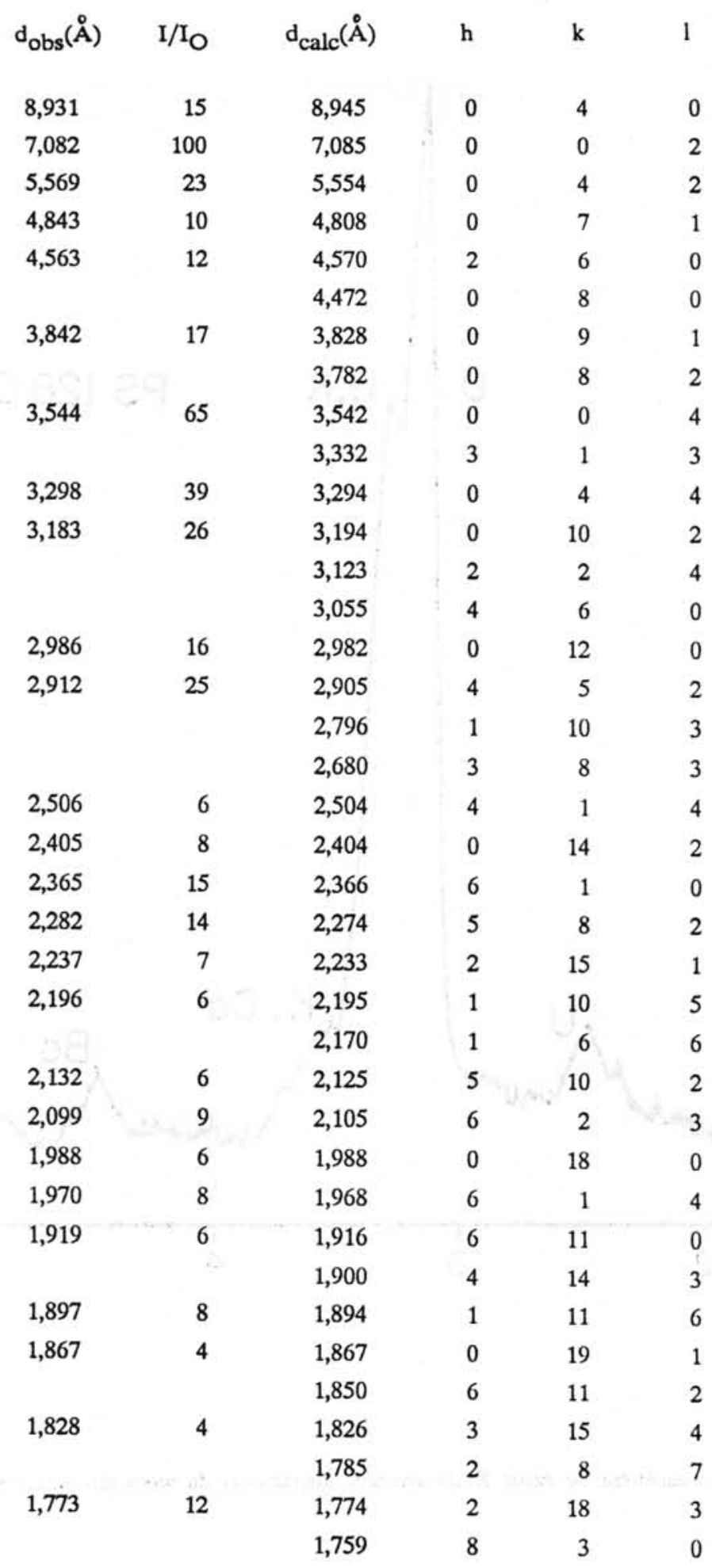


TABELA 2 - Parâmetros de cela unitária da weeksita

\begin{tabular}{clc} 
& \multicolumn{1}{c}{$\mathbf{1}$} & $\mathbf{2}$ \\
$\mathrm{a}(\AA)$ & $14,26(2)$ & $14,23(2)$ \\
$\mathrm{b}(\AA)$ & $35,88(10)$ & $35,78(5)$ \\
$\mathrm{c}(\AA)$ & $14,20(2)$ & $14,17(3)$
\end{tabular}

1. Thomas Range, Utah, Estados Unidos (OUTERBRIDGE et al., 1960), 2. Perus, São Paulo, Brasil (este trabalho). 